\title{
A review on therapeutic management for oral chronic graft-versus-host disease
}

\author{
Mina Khayamzadeha ${ }^{a}$ Hanieh Kavianib
}

'Department of Oral and Maxillofacial Medicine, Faculty of Dentistry, Tehran University of Medical Sciences, International Campus, Tehran, Iran.
bDepartment of Oral and Maxillofacial Radiology, Faculty of Dentistry, Tehran University of Medical Sciences, International Campus, Tehran, Iran.
Corresponding Author: Hanieh Kaviani (E-mail: Haniehkaviani@yahoo.com )

(Submitted: 19 June 2020 - Revised version received: 07 July 2020 - Accepted: 14 August 2020 - Published online: 30 October 2020)

\begin{abstract}
Chronic graft-versus-host disease (cGVHD) is one of the main complications of transplantation in allogeneic hematopoietic cells which results in reduced quality-of-life. cGVHD mostly affects the oral cavity, producing various symptoms and manifestations. It can lead to both short- and long-term complications such as limited oral intake, mucosal sensitivity, secondary malignancy, and even early death. GVHD is an allo- and autoimmune disorder with a variable clinical course that commonly involves various tissues and organs. It can occur in both the acute and chronic forms. In the case of CGVHD, a large number of organs are affected including the oral cavity. However, in some cases of CGVHD only the oral cavity gets affected. The clinical indications of chronic oral GVHD may include sclerosis, hyperkeratotic plaques, lichenoid lesions, and limited oral aperture. The level of oral involvement is commonly mild, but medium to high severity erosive as well as ulcerated lesions may also occur. Although diagnosed through clinical examination, its confirmation is usually done by biopsy study. The first treatment option is using local corticosteroids with the potency to treat half of patients. Extracorporeal photopheresis and systemic corticosteroids are in the next ranks. Patient survival after diagnosis of oral chronic GVHD is within 4.5 years in $50 \%$ of the cases, thus it is not regarded as a determinant factor in patient survival. This study attempted to provide a detailed approach for clinical diagnosis and management of patients suffering from oral cGVHD. It particularly considered the factors such as differential diagnosis, symptom control, screening for, and prevention of secondary complications. It tried to provide practical and relevant considerations and recommendations for all clinicians who deal with oral CGVHD patients in order to achieve improved care and outcomes.

Keywords: Chronic graft-versus-host disease (cGVHD), risk factors, oral GVHD, biological pathogens, therapeutic management
\end{abstract}

\section{Introduction}

To ensure reconstruction of the recipient immune system after grafting from the donor cells, the recipient is subjected to immunosuppressive and myelosuppressive conditioning treatments before transplantation, thereby avoiding the problems of rejection. ${ }^{1}$ However, the donor's immunocompetent T-lymphocytes may detect the expressed antigens by the recipient cells as foreign after transplantation, hence provoking an immune reaction according to the intensity of inflammatory responses which may damage the tissues and organs of the recipient. These circumstances known as graft-versus-host disease (GVHD) is a result of the incompatibility between the antigens of human leukocyte antigen (HLA) system in recipient and donor. ${ }^{2}$

Allogenic hematopoietic stem cell transplantation (HSCT) is a common procedure used for treatment of various benign and malignant hematological diseases. HSCT has some complications, most frequent and serious of which is GVHD, regarded as the major cause of late mortality not associated with underlying disease process. ${ }^{3,4}$ The risk of GVHD is considered as an important cause of insufficient popularity of HSCT. ${ }^{5}$ GVHD is an allo- and autoimmune disorder with a variable clinical course that commonly involves various tissues and organs. It has a negative effect on life expectancy of patients with this disorder. The prevalence of acute GVHD (aGVHD) has remained almost constant in the last 10 years, however, cGVHD has increased. ${ }^{6}$ The reason for this is the use of hematopoietic cells rather than of bone marrow transplants, the lymphocyte infusions especially into decreased intensity allotransplants, using donors who are not wholly
HLA-compatible with or without blood ties to the recipient, performing more transplants in the elderly, and the number of yearly performed transplants.

In allogenic transplant patients, a rate of aGVHD between $50 \%$ and $70 \%$ is observed, while this rate for cGVHD is between $30 \%$ and $50 \% .{ }^{8}$ In contrast to previous few years, these two forms of GVHD is usually distinguished from each other by their clinical characteristics rather by timing criteria. ${ }^{1,3}$ The aGVHD usually affects liver, gastrointestinal tract, and skin and is potentially fatal. In the cGVHD, the oral cavity is mainly affected, and sometimes may be the only affected part of the body by the disease. ${ }^{9}$ The cGVHD is more common in first 3 years post-transplantation, and normally developed by the acute form. The cGVHD has similar clinical characteristics to the other immune-mediated diseases including lupus erythematosus, lichen planus, and systemic sclerosis. The drugs used for aGVHD prevention are not effective on preventing cGVHD. ${ }^{6}$ Although there are no specific treatments for GVHD, corticosteroids and immune modulators can be used for this condition. ${ }^{10}$

This study attempts to provide a modified remedial method for oral cGVHD within these criteria: (I) identifying the most important causes of oral cGVHD development, (II) the pathogenic role of the T-cells, (III) the major risk factors for cGVHD, (IV) determining when a biopsy is needed to confirm the oral cGVHD diagnosis, $(\mathrm{V})$ the frequency of the oral cavity affecting by cGVHD, and (VI) determination of the effectiveness rate of oral cGVHD treatment. 


\section{Material and Methods}

A systematic review of recent literature on topical agents used for treatment of the inflammatory mucosal lesions found in oGVHD patients was conducted. In order to identify potentially relevant articles with the subject of this study, an extensive research was performed over Pubmed, National Library of Medicine's Medline, and Embase electronic databases using keywords "GVHD," "chronic GVHD," "graft vs. host," "diagnosis," "prevention," "grading," and "treatment”. Accordingly, 274 articles were found from the mentioned databases which was further categorized into 4 main groups including diagnosis, prevention, grading, and treatment. After elimination the unrelated articles, finally 36 articles were selected as related articles within this comprehensive study. To obtain more detailed studies on the subject of this study, 9 other relevant articles were identified from relevant databases. Eventually, 46 publications were included in this review (Fig. 1).

\section{Oral cGVHD Epidemiology}

The oral cavity is usually affected in cGVHD, so that around $80 \%$ of patients with cGVHD demonstrate oral cavity involvement. When diagnosis of cGVHD, oral characteristics are commonly present, demonstrating the initial clinical manifestations. Oral involvement can be regarded as the most common single-site involved in cGVHD patients. Although there are no significant difference in severity, extent, and complications of oral cGVHD among all age groups, the overall occurrence of cGVHD in adults is higher than in pediatric patients. ${ }^{13}$ There are several factors associated with higher risk of cGVHD incidence after allogeneic HCT such as HLA mismatch, antecedent acute GVHD, and stem cell source, however, risk factors specific of oral cGVHD have remained unknown.

\section{Acute Graft-Versus-Host Disease}

GVHD disease can be naturally categorized into aGVHD and cGVHD. Previously, this categorization was based on inception time of incidence in which aGVHD specified as incidence within 100 days of post-transplantation. ${ }^{15}$ Recently, GVHD status is largely defined based on clinical properties. Presentation of acute symptoms such as liver dysfunction, upper and lower gastrointestinal involvement, oral mucositis, and maculopapular cutaneous lesions can be classified as classic, recurrent, persistent, or late-inception aGVHD. Incidence of aGVHD within 100 days post-allogeneic HSCT is defined as classic aGVHD, while incidence later than 100 days after

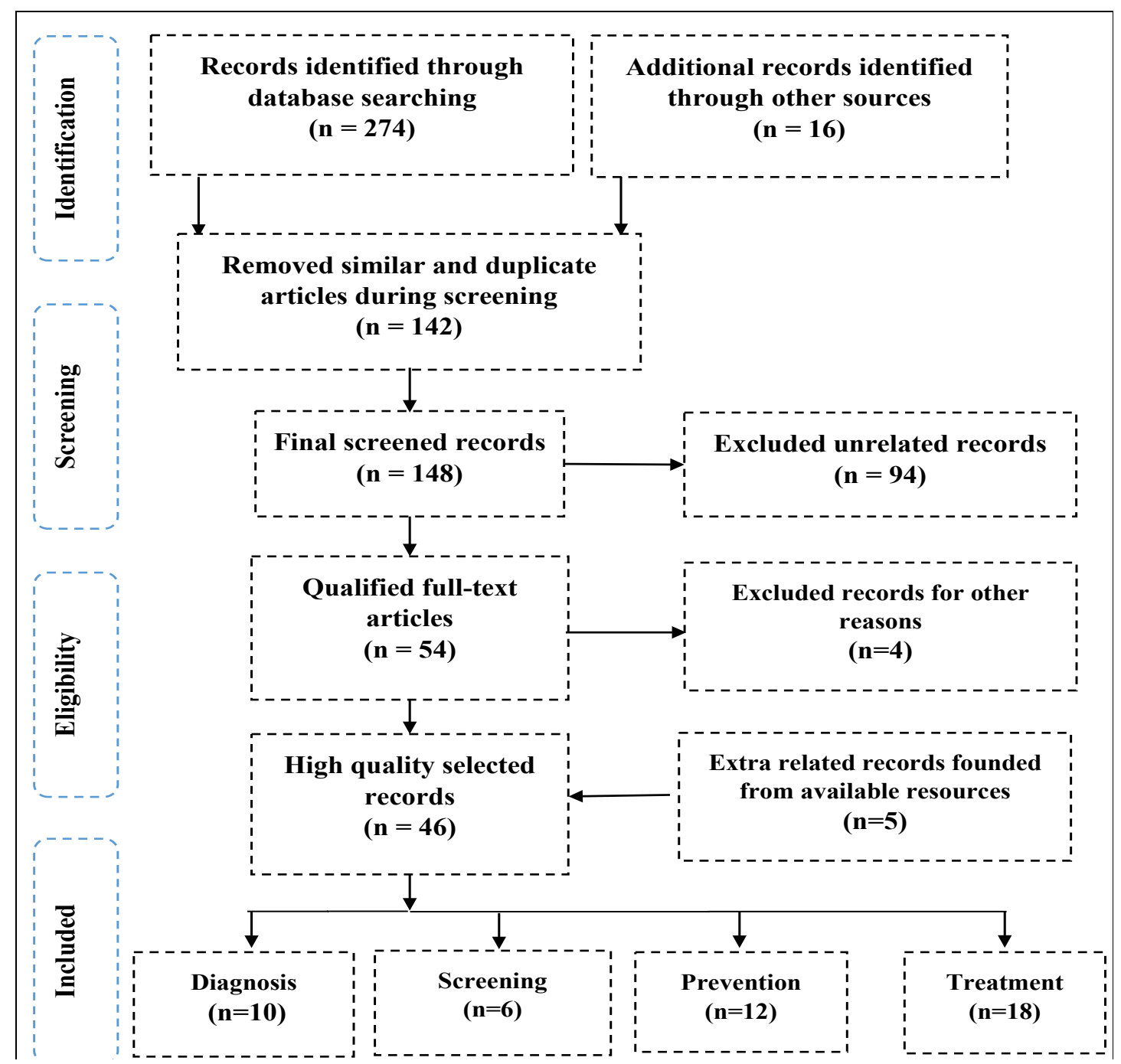

Fig. 1. The procedure of choosing relevant articles used in the present study in accordance with PRISMA method. 
allogeneic HSCT indicates recurrent, persistent or late-inception aGVHD. ${ }^{16}$

\section{Chronic Graft-Versus-Host Disease}

cGVHD is the most frequent complication of post-allogeneic HSCT, which occurs in about $50 \%$ of patients who survive more than 1 year after transplantation. Manifestations of cGVHD is commonly developed within the first 3 years following HSCT. Either the involvement of one organ or several areas of the body is possible. ${ }^{16}$ cGVHD may target the mouth, eyes, skin, liver, lungs, GI tract, genitourinary tract, and joints of patients, producing pain and function disability, thus weakening the quality-of-life. Moreover, it is considered as the major cause of death among survivors of transplant, so that it accounts for about $70 \%$ of deaths before 5 years of transplantation. ${ }^{70}$

This high rate of morbidity and mortality can largely be attributed to immune dysregulation and suppression which result in recurrent infections. ${ }^{16}$ The cGVHD syndrome has clinical and histological similarities to many immunologic disorders such as Sjögren's syndrome, scleroderma, bronchiolitis obliterans, primary biliary cirrhosis, chronic immunodeficiency, and immune cytopenias. As a result, cGVHD is defined as a multisystem autoimmune and alloimmune disorder which is specified by immune deficiency, immune dysregulation, end-organ dysfunction, and reduced survival. ${ }^{16}$

\section{Clinical Features and Risk Factors of Oral CGVHD}

Although usually considered as a singular clinical entity, oral cGVHD has its own clinical features in terms of sclerodermatous, mucosal, and salivary gland involvement, each of which can result in significant morbidity and late complications. Clear understanding of their distinct clinical features is necessary to appropriate diagnosis and effective management. ${ }^{7}$ The risk factors described for cGVHD includes HLA inconsistency or lack of blood ties between the recipient and donor; a male recipient and female donor; higher ages of the recipient and donor; child-bearing in female donors; donor lymphocyte infusions; the transplantation of mobilized peripheral blood cells; and a history of aGVHD. ${ }^{14,18}$ The risk factors described for cGVHD includes HLA inconsistency or lack of blood ties between the recipient and donor; a male recipient and female donor; higher ages of the recipient and donor; child-bearing in female donors; donor lymphocyte infusions; the transplantation of mobilized peripheral blood cells; and a history of aGVHD. ${ }^{14,18}$ Among these, three factors of a male recipient and female donor, higher ages, and the transplantation of mobilized peripheral blood cells seem to be especially associated to cGVHD. The factors of conditioning treatment intensity before transplantation and whole body irradiation appears to have no effect on cGVHD occurrence.

Although the mechanism of the disease in terms of immunopathogenic is not completely apparent, the major provoking factor of GVHD is known to be reactivity of donor T-cells against the recipient tissues which occurs as intensified direct or indirect inflammatory responses. ${ }^{3,19}$ Despite the existence of common risk factors, each type of GVHD has its own risk factors, suggesting the difference between their underlying pathogenesis. Activation of the interferon-1 pathway seems to have a role in oral cGVHD. ${ }^{6}$ Some authors have specified the thymus gland destruction by alloreactive $\mathrm{T}$ cells as the major provoking factor in cGVHD, arguing that thymopoiesis and $\mathrm{T}$ cell renovation phenomena may be observed after autologous hematopoietic cell transplantation, and cGVHD is not common. It has been proposed that cGVHD is distinguished via a humoral immune response mediated by Th2 lymphocyte, while aGVHD is specified by a cellular immune response mediated by Th1 lymphocyte. ${ }^{6}$

Both the B lymphocytes and T-cells are involved in the depletion of general immune tolerance. The capability of B lymphocytes to produce antibodies on one hand, and the good outcomes obtained in using anti-CD20 drugs for autoimmune diseases with similar features to those of GVHD on other hand, caused many recent studies on the role of the B lymphocytes in GVHD pathogenesis. Although there is no established autoantibody panel specific to cGVHD, more symptoms are seen in patients with autoantibodies and cGVHD. ${ }^{20}$ Moreover, antigen-presenting cells like dendritic cells as well as cytokines like B-cell activating factor which belongs to the family of tumor necrosis factor appears to play a role. ${ }^{20}$ Tables 1 and 2 demonstrate the criteria for characterization of different GVHD presentation.

\begin{tabular}{|c|c|c|c|}
\hline \multicolumn{4}{|c|}{ Diagnostic differentiation between aGVHD and cGVHD. } \\
\hline \multicolumn{2}{|c|}{ aGVHD } & \multicolumn{2}{|c|}{ cGVHD } \\
\hline \multirow{2}{*}{\multicolumn{2}{|c|}{$\begin{array}{l}\text { At least one diagnostic or } \\
\text { distinctive manifestation } \\
\text { of cGVHD persists with } \\
\text { no characteristic features } \\
\text { of aGVHD without time } \\
\text { restrictions. }\end{array}$}} & \multicolumn{2}{|c|}{$\begin{array}{c}\text { Maculopapular rash } \\
\text { Secretory hepatitis } \\
\text { Nausea and vomiting } \\
\text { Anorexia }\end{array}$} \\
\hline & & $\begin{array}{l}\text { Occurring in } 100 \text { days } \\
\text { post-transplant, or donor } \\
\text { lymphocyte infusion, with } \\
\text { no diagnostic or distinctive } \\
\text { demonstrations of cGVHD }\end{array}$ & $\begin{array}{l}\text { After } 100 \text { days post- } \\
\text { transplant, or donor } \\
\text { lymphocyte infusion, with } \\
\text { no diagnostic or distinctive } \\
\text { demonstrations of cGVHD }\end{array}$ \\
\hline Classic cGVHD & Overlap syndrome & Classic aGVHD & $\begin{array}{c}\text { Recurrent or late-inception } \\
\text { aGVHD }\end{array}$ \\
\hline
\end{tabular}




\section{Table 2. Diagnostic clinical signs of cGVHD. Derived from Maria et al.21}

\begin{tabular}{|c|c|c|}
\hline Organ or location & CGVHD & $\begin{array}{l}\text { Common characteristics observed in both } \\
\text { the aGVHD and cGVHD }\end{array}$ \\
\hline Skin & $\begin{array}{c}\text { Poikiloderma } \\
\text { Morphea-like features } \\
\text { Lichen planus-like features } \\
\text { Lichen sclerosus-like features }\end{array}$ & $\begin{array}{c}\text { Erythema } \\
\text { Pruritus } \\
\text { Maculopapular rash }\end{array}$ \\
\hline Mouth & $\begin{array}{l}\text { Lichen-type features } \\
\text { Restriction of mouth opening } \\
\text { from sclerosis } \\
\text { Hyperkeratotic plaques }\end{array}$ & $\begin{array}{l}\text { Gingivitis } \\
\text { Erythema } \\
\text { Mucositis } \\
\text { Pain }\end{array}$ \\
\hline Genitalia & $\begin{array}{l}\text { Lichen planus-like features } \\
\text { Vaginal scarring or stenosis }\end{array}$ & \\
\hline Gastrointestinal tract & $\begin{array}{l}\text { Esophageal web } \\
\text { Strictures or stenosis in the upper } \\
\text { to mid third of the esophagus }\end{array}$ & $\begin{array}{l}\text { Anorexia } \\
\text { Diarrhea } \\
\text { Nausea } \\
\text { Vomiting } \\
\text { Weight loss }\end{array}$ \\
\hline Lung & Bronchiolitis obliterans & \\
\hline Liver & & $\begin{array}{l}\text { Overall bilirrubin, alkaline phosphatase }>2 x \\
\text { upper limit of normal } \\
\text { ALT or AST }>2 x \text { upper limit of normal }\end{array}$ \\
\hline Muscles fascia, joints & $\begin{array}{c}\text { Fasciitis } \\
\text { Joint rigidity or contractures secondary to } \\
\text { sclerosis }\end{array}$ & \\
\hline
\end{tabular}

\section{Chronic GVHD Immunopathogenesis}

The basic cGVHD pathogenesis requires alloreactive donor T-cells to detect and invade the host tissues in immunocompromised recipients. ${ }^{22}$ Currently, it is known that there is a nuanced interaction between multiple immune cell types of the recipient and donor. The factors such as inflammation induced by the post-transplant infectious and conditioning regiment results in complexity of such a relationship. CGVHD has several fibrotic and autoimmune characteristics. The cGVHD syndrome has clinical and histological similarities to many classic autoimmune disorders such as Sjögren's syndrome, scleroderma, primary biliary cirrhosis, systemic lupus erythematosus, and lichen planus. ${ }^{16}$ The procedure consists of a potent pro-inflammatory T-cell component in addition to B cells involvement and regulatory T-cells. ${ }^{23}$

Absence of a preclinical model to simulate the clinical aspects of human CGVHD is the major challenge in comprehending the immunopathogenesis of cGVHD. The focus of animal models are largely on mortality and weight loss, missing the major MHC factors. Despite using some minor-MHC mismatch models, none of them sufficiently replicate the temporal and multiorgan features of human cGVHD. ${ }^{24}$ It is challenging to set up prospective longitudinal studies in patients with $\mathrm{cGVHD}$, since this requires long-term tracking of the patients. The samples used in these studies are often limited to clinically indicated tissue biopsies, clinical laboratory values, and peripheral blood with a variable nature, making it difficult to get a clear conclusion on cGVHD development and pathogenesis. Below, the results of both animal models and studies of human cGVHD are provided with more emphasis on human data. Also, a discussion on the contribution of various factors and cell types to pathogenesis of cGVHD is presented. ${ }^{25}$

\section{Oral cGVHD}

\section{Oral cGVHD Clinical Presentation}

Various organs can be affected by cGVHD, of which the skin is most commonly involved organ followed by the oral cavity with the prevalence of $45-83 \%$ in cGVHD patients. ${ }^{26}$ Oral cGVHD can manifest as salivary gland dysfunction, restricted mouth opening and mucosal lesions. There are a variety of clinical manifestation of cGVHD in severity and type of tissue changes, and any location in oral cavity can be attacked by cGVHD. Clinical examination involved tongue, labial and buccal mucosa, lips, gingiva, floor of mouth, hard and soft palate, as well as mouth movement, and salivary function evaluations. ${ }^{26}$ Subjective oral dryness, oral pain, and sensitivity of the patient, and oral movement restriction or dysfunction can be regarded as important elements in clinical diagnosis of cGVHD, and convince the practitioner of performing more site specific evaluations. ${ }^{27}$

\section{Oral Mucosal Lesions}

The affected area of intraoral mucosa and the severity of lesion could vary and should be evaluated when examination of oral mucosal lesions. ${ }^{26}$ Oral mucosal lesions of cGVHD are usually characterized as ulcerative, lichenoid, mucoceles, or erythema (Fig. 2). ${ }^{16}$ Erythema, described as the oral mucosa redness with no breakdown in tissue, is typically a symptom of inflammation or infection. It can be associated with edema and/or atrophy of the mucosa (Fig. 1a). Complaint of oral sensitivity with mucosal erythema is common among patients. Lichenoid oral cGVHD, defined as lacey lines, or milky to white reticular streaks on oral mucosa, is similar to the Wickham's striae seen in oral lichen planus (Fig. 2b). These can be a sign of 


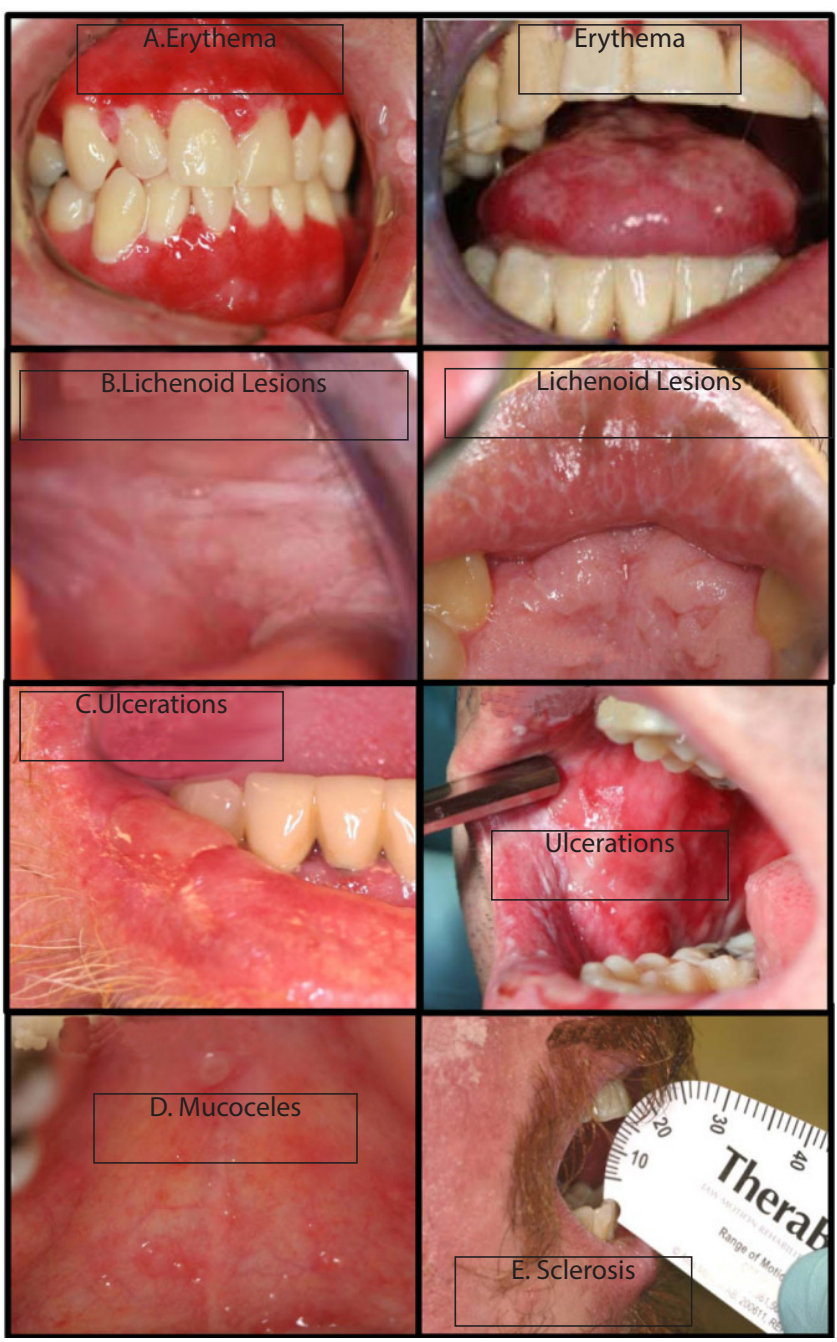

Fig. 2. Various clinical manifestations of oral cGVHD. (a) erythema of the tongue and oral mucosa, (b) lichenoid lesions occurred on the lips, buccal mucosa, and other regions of the oral cavity, (c) oral ulcers, (d) mucoceles formed on the hard palate and occasionally below labial mucosa, and (e) peri-oral sclerosis that restricts the opening of mouth. Derived from JW et al.28

hyperkeratotic leukoplakias which is white plaques or thickened, hyperplastic mucosa. The oral mucosal lesions are not painful most of the times and considered as diagnostic signs for oral cGVHD while evaluation of post-HSCT. ${ }^{16}$

Oral mucosa breakdown results in ulcerations which are associated with pseudomembranes, because weak healing of wounds developed over the time (Fig. 2c). Ulcerations may be painful to some extent that result in reduced eating and prevention of oral hygiene. ${ }^{26}$ Infection can easily reach to patient's bloodstream through oral cavity ulcers which completely breakdown the solidarity of oral mucosal barrier. Mucoceles are surface subepithelial secretions of saliva which are transferred from minor salivary glands to the epithelial-connective tissue interface induced by fibrotic occlusions of the glandular duct openings. ${ }^{26}$ They manifest as dome-shaped lesions filled by fluid which are surrounded and covered by oral mucosa (Fig. 2d). They are commonly asymptomatic and seen solely on the lips and palate. Salivary ducts may be blocked by salivary gland inflammation, which is deteriorated by reduced secretion and increased viscosity of saliva, results in mucocele formation. ${ }^{16}$

\section{Salivary Dysfunction}

Patients with oral cGVHD grow inflammatory damages to salivary gland tissue, experiencing reduced salivary flow and dry mouth. Salivary dysfunction induced by cGVHD have similar characteristics with Sjögren syndrome manifestations, that is, xerostomia or subjective dry mouth, and hyposalivation or reduction of objective saliva flow. ${ }^{29}$ A patient with dry mouth experiences problems in swallowing, chewing, speaking, increased dental, and oral mucosal disease such as oral caries and Candida infections (Fig. 3A-C).$^{30}$ Salivary dysfunction induced by oral cGVHD presents different manifestations and appears to be a distinct entity from the mucosal. There are few correlations between their manifestations. However, evaluation of cGVHD requires a formal salivary function test as an important symptom and indication in diagnosis, staging, and treatment of the disease. ${ }^{29}$

\section{Diagnosis of Oral cGVHD}

Oral cGVHD diagnosis is mainly based on the precedent, findings of clinical examination, and beginning time of signs and symptoms, for example, the time after Allogeneic hematopoietic cell transplantation (HCT), weakening of immunosuppressive regiment, and involvement of other affected regions in cGVHD. ${ }^{13}$ The National Institutes of Health Consensus Development Project on Criteria for Clinical Trials in Chronic Graft-Versus-Host Disease has introduced a standardized criteria regarding the diagnosis of salivary gland and oral mucosal cGVHD, though these criteria have not been validated and were based on the opinion of experts (Table 3 ).

Diagnostic aspects required to make a clinical decision on oral (mucosal) cGVHD are hyperkeratotic plaques and lichenoid or reticular lesions along with ulcerative and erythematous variations without lichenoid reticulations manifestation. However, these aspects are considered to be "distinctive",

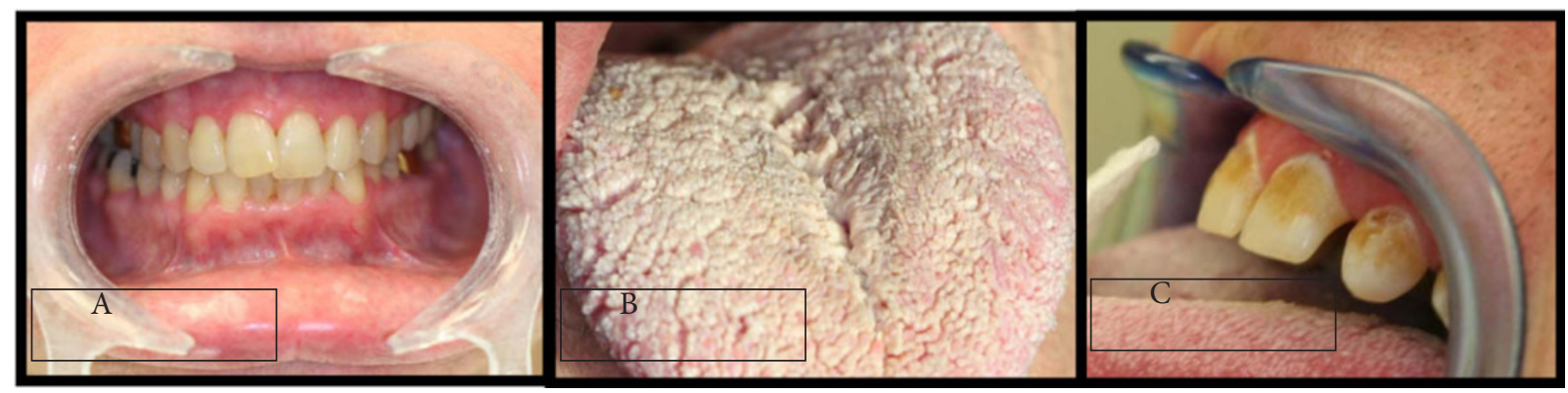

Fig. 3. Extreme dry mouth induced by salivary gland dysfunction (A). This paves the way for fungal overgrowth and opportunistic infections (B), and weakens the remineralization of tooth enamel, producing cervical carious lesions (C). Derived from JW et al.28 
not diagnostic. ${ }^{31}$ In the cases that making a clinical diagnosis is difficult, the biopsies of minor salivary gland and/or oral mucosal are helpful, though they are typically not necessary in practice. In overall, the diagnosis of salivary gland cGVHD is more difficult than oral mucosal cGVHD, due to the more obvious clinical characteristics and restricted differential diagnosis of oral mucosal cGVHD. ${ }^{32}$ The staging score established by The National Institutes of Health is a simple measure for determining the functional impact of oral cGVHD. It is also useful to evaluate the changes in severity of oral cGVHD over the time (Table 4).

It is essential that oral cGVHD be differentiated from other common oral conditions that do not require therapy. To distinguish oral cGVHD from other common oral complications is essential, since they do not need therapy. These complications include: lesions induced by cheek biting with a spread and ragged" white appearance; linea alba which is a hyperkeratotic white line, forming along the bite plane; geographic tongue, which appears in the form of erythematous and atrophic patches, enclosed by circular white hyperkeratotic alterations that grow and wane regularly; and leukoedema, which is white faintly reticular that entirely disappears when the tissue be stretched. ${ }^{1}$ Although not routinely performed, tissue biopsy is only laboratory test available for confirmation of oral cGVHD diagnosis, thus, experience and good diagnostic skills are critical in diagnosis of this condition. In the cases with equivocal findings or atypical presentations, consultation with oral medicine specialty can be beneficial, especially when indications are disproportionate with clinical properties. ${ }^{3}$

\section{Oral cGVHD Predictive Factors}

It is reported that a history of acute GVHD and using peripheral blood stem cell source are the risk factors for oral cGVHD. ${ }^{34}$ Moreover, the involvement of salivary gland in oral cGVHD has been reported to be a result of pre-transplant conditioning TBI. ${ }^{35}$ The results of a recent comprehensive multivariate logistical regression analysis showed that oral cGVHD had significant relationships with mouth pain in patients as well as with a number of inflammation laboratory markers such as higher levels of total complement and lower levels of albumin. ${ }^{36}$

The oral cGVHD can have many health consequences such as reduced oral epithelial integrity and limited repair ability, increased oral infections, oral pain, negative impacts on eating, nutrition, speech, quality-of-life, and increased caries ris. ${ }^{19}$ Oral cGVHD is not related to poor long-term survival, but it has negative impacts on functional capacity, oral health, symptoms, and quality-of-life of patients. Oral cGVHD has is directly related to the severity of patients' self-reported oral pain. ${ }^{37}$ The risk of extensive cervical decay is very high in oral cGVHD patients during the first 2 years of transplantation. Patients with oral cGVHD have been reported to experience taste changes and higher levels of oral pain and dryness than patients without oral cGVHD. ${ }^{38}$. Moreover, the risk of reduced oral cavity-related quality-of-life and lower scores of body mass index is increased in oral cGVHD patients. Atrophy or dysfunction of salivary gland in patients results in difficulty swallowing, higher risk of occurring dental carious lesions as the result of impaired remineralization, and repetitious co-infections because of decreased salivary defenses as secretary IgA. ${ }^{19}$

\section{Oral cGVHD Management}

Systemic corticosteroids alone or in combination with other immunomodulatory agents are required for cGVHD, particularly in the cases with multisystem involvement. This will provide adequate control of oral disease symptoms in many cases. Management of cGVHD by systemic immunosuppressive therapy requires 2-3 years averagely. However, the data on the long-run course and management approaches of oral

\begin{tabular}{|c|c|c|}
\hline \multirow{2}{*}{$\begin{array}{l}\text { Oral mucosal } \\
\text { cGVHD }\end{array}$} & Signs & $\begin{array}{l}\text { Hyperkeratotic plaques, Lichen-type appearance, Erythema/atrophy, Atrophic glossitis, Ulcerations } \\
\text { with pseudomembranes, Superficial mucoceles }\end{array}$ \\
\hline & Symptoms & $\begin{array}{l}\text { Taste changes, Sensitivity to brushing/mint-flavored toothpaste, Sensitivity to foods/drinks including } \\
\text { acidic foods, spicy/seasoned foods, alcoholic beverages and mouth rinses containing alcohol, hard, } \\
\text { crunchy or crusty foods, salty foods, warm foods or drinks. }\end{array}$ \\
\hline \multirow[t]{2}{*}{$\begin{array}{l}\text { Salivary gland } \\
\text { CGVHD }\end{array}$} & Signs & $\begin{array}{l}\text { Saliva deficiency or lack of mouth floor, Thickened or sticky saliva, Ropey or foamy saliva, } \\
\text { Oropharyngeal candidiasis, Atrophic mucosa, Food debris inside the mouth, Dental caries at the } \\
\text { cervical margins and interproximal, Tongue "clicking" during speaking, repeated water sipping, } \\
\text { Inability to swallow dry foods without fluids }\end{array}$ \\
\hline & Symptoms & $\begin{array}{l}\text { Throat constriction and difficulty swallowing, Difficulty chewing, Difficulty speaking, Xerostomia, } \\
\text { Sensitivity to foods or drinks, Nightly waking due to severe dryness, Taste alterations }\end{array}$ \\
\hline \multirow{2}{*}{ Sclerotic cGVHD } & Signs & Leathery skin, Mucosal bands, limitation in mouth opening from sclerosis \\
\hline & Symptoms & Jaw pain, Difficulty eating, Tightness \\
\hline
\end{tabular}

\begin{tabular}{|c|c|c|c|}
\hline Zero & I & $\|$ & III \\
\hline Asymptomatic & $\begin{array}{l}\text { There are mild symptoms along with } \\
\text { disease signs, but oral intake is not } \\
\text { significantly limited. }\end{array}$ & $\begin{array}{l}\text { There are moderate symptoms } \\
\text { along with disease signs. Oral intake } \\
\text { is partially limited. }\end{array}$ & $\begin{array}{l}\text { There are severe symptoms } \\
\text { along with disease signs. Oral } \\
\text { intake is severely restricted. }\end{array}$ \\
\hline
\end{tabular}


cGVHD therapy are unavailable. ${ }^{39}$ According to our experience, management of many patients with oral cGVHD require long-term intensive ancillary therapy, even after stoppage of therapies with systemic immunosuppressives. The accessibility of local and topical therapies is beneficial to oral cavity, owing to the fact that continuous oral disease is usually manageable without systemic immunosuppression. Similarly, in the cases with limited oral involvement, ancillary measures without systemic therapy may be sufficient to manage cGVHD. ${ }^{1,3}$

Oral cGVHD therapy aimed to reduce the symptoms, eliminate the painful lesions, prevention, and management of secondary complications. All patients need to be informed on the importance of good oral hygiene, keep daily flossing and tooth brushing, and visit professional dental clinics at least twice annually. There are no proofs for antibiotic prophylaxis in patients who their cGVHD has been treated, however, because of precaution aspects during immune reconstitution, most centers suggest that elective dental visits to be restricted during the first year after transplantation. ${ }^{31}$ Toothpaste contains sodium lauryl sulfate and flavoring agents, resulting severe sensitivity in patients with oral cGVHD. These patients should be recommended to use children's toothpaste which are free of sodium lauryl sulfate and less intensely flavored. Moreover, oral cGVHD patients cannot tolerate mouthwashes that are heavily flavored agents and those containing alcohol, and should be avoided. The tolerability of oral cGVHD patients is largely variable. They may face difficulty to eat outdoor where food options are limited and highly seasoned. Patients may need to be avoided from consumption of rough/hard, spicy, acidic, hot, and carbonated drinks/foods. In some patients, nutritional counseling may be required, although it is not routinely indicated. ${ }^{40}$

\section{Tooth Decay}

Due to the reduced antifungal and anticariogenic activities in patients with salivary gland cGVHD, they are at higher risk for evolving secondary infectious complications. Patients with oral cGVHD often developed accelerated and rampant dental caries due to under-recognized reasons, resulting widespread dental therapy, teeth extraction, and considerable economic and social costs. ${ }^{41}$ Dental caries is more prominent at interproximal surfaces and cervical margins where dental plaque in absence of salivary flow can be accumulated. The difficulty of tooth brushing in patients with oral mucosal cGVHD may result in neglecting oral hygiene, exacerbating the problem of salivary gland changes. Apart from the effects on teeth, the risk of recurrent oral candidiasis threatens the patients with salivary gland cGVHD, especially if they are being treated by topical corticosteroid therapy. ${ }^{42}$

Dental caries prevention is an important constituent of salivary gland cGVHD management. We recommend the measures given in Table 5 for all patients with clinically significant disease. It is of great importance to continuously notify these patients of maintaining good oral hygiene and non-cariogenic diet. In the case of intense salivary gland hypofunction in which brushing after eating is impossible, patients should be encouraged to water-rinse their mouths after eating. ${ }^{43}$ There are increasing evidence on using calcium- or phosphate-based remineralizing agent (e.g., GC MI Paste Plus, GC America) just before applying the topical fluoride. ${ }^{44}$ In order to further protection, dentists can apply fluoride varnish twice a year during patient referrals.

\section{Oral cGVHD Treatment}

Oral pain or soft tissue sensitivity is the major complaint of patients with oral cGVHD. Although several formulations of lidobenalox (magic mouthwash) exist, the basic three ingredients are the same which include an antihistamine (Benadryl), a local anesthetic (lidocaine), and an aluminum/magnesium hydroxide $\left(\right.$ Maalox $\left.^{\oplus}\right)$ to coat the oral cavity. Two other formulations for this compound rinse are corticosteroid and antifungal ingredients which are beneficial for cGVHD patients. Liquid dyclonine (usually $0.5 \%$ ) is a potent topical anesthetic which can be prescribed for palliation of pain in the cases with

\begin{tabular}{|c|c|c|c|}
\hline Late complication & Prevention & Screening & Management \\
\hline $\begin{array}{l}\text {-Oral squamous } \\
\text { cell carcinoma }\end{array}$ & $\begin{array}{l}\text { - Smoking interruption } \\
\text { - Moderate consumption of } \\
\text { alcohol }\end{array}$ & $\begin{array}{l}\text { - Yearly clinical examination } \\
\text { - Atypical/suspicious lesions biopsy }\end{array}$ & $\begin{array}{l}\text { - Visiting a multidisciplinary head- } \\
\text { and-neck oncology center }\end{array}$ \\
\hline $\begin{array}{l}\text {-Rampant dental } \\
\text { caries }\end{array}$ & $\begin{array}{l}\text { - Minimal consumption of } \\
\text { refined carbohydrates, especially } \\
\text { soft drinks containing sugar } \\
\text { - Brushing at least twice a day } \\
\text { after eating } \\
\text { - Daily flossing } \\
\text { - Daily applying of fluoride 1.1\% } \\
\text { gel paint on or in custom trays } \\
\text { - Application of remineralizing } \\
\text { agent with fluoride } \\
\text { - Application of professional } \\
\text { fluoride varnish }\end{array}$ & $\begin{array}{l}\text { - The risk is greater in patients with } \\
\text { considerable salivary gland cGVHD } \\
\text { - The risk is greater in patients with } \\
\text { orofacial sclerotic cGVHD } \\
\text { - The risk is greater in in patients which } \\
\text { severe mucosal disease who avoiding } \\
\text { oral hygiene } \\
\text { - Teeth examination for any evidence of } \\
\text { cervical demineralization or decay } \\
\text { - Referral to dental clinics twice a year } \\
\text { - Examination of soft and hard tissues } \\
\text { - Annual bitewing radiographs }\end{array}$ & $\begin{array}{l}\text { - Treatment of dental caries soon after } \\
\text { diagnosed } \\
\text { - Follow-up carefully for new or } \\
\text { recurrent dental caries } \\
\text { - Reinforcement of dietary habits and } \\
\text { oral hygiene } \\
\text { - Reinforcement of daily preventive } \\
\text { measures }\end{array}$ \\
\hline -Fibrosis & - Unknown preventive measures & $\begin{array}{l}\text { - Asking patients on the existance of any } \\
\text { tightness /limited opening } \\
\text { - Widespread sclerotic skin disease, } \\
\text { particularly if the patient's neck is } \\
\text { involved } \\
\text { - examination of intraoral buccal fibrotic } \\
\text { bands via palpation }\end{array}$ & $\begin{array}{l}\text {-Physical therapy } \\
\text {-Intralesional steroid therapy } \\
\text {-Surgery } \\
\text {-Systemic therapy for systemic } \\
\text { involvement }\end{array}$ \\
\hline
\end{tabular}


severe and intolerable pain. Additionally, long- or short-acting narcotics can be used before meals to allow for adequate nutrition. ${ }^{10}$

Titration of effective systemic therapy is used to manage oral cGVHD. Moreover, topical immunosuppressive treatment as well as ancillary supportive care may be also required for this purpose. Oral cGVHD flares can be occurred in the following situations; when a patient stops or tapers a systemic immunosuppression, or when adjustment of drug levels. Currently, management of mucosal symptoms of oral cGVHD is largely included the use of topical corticosteroids with high and ultra-high potency (Table 6), calcineurin inhibitors and analgesics. ${ }^{44}$ The topical treatments are not always efficient. They may breakdown in mucosal integrity, increasing the risk of systemic absorption in patients with oral cGVHD. To improve the efficacy, some topical agents may be added to oral adhesive or oral rinse formulation. Nevertheless, there are no clinical trials to determine the specific agents and dosing plans. ${ }^{31}$

Oral rinses are largely applied in management of mucosal disease due to the effectiveness and easiness of this delivery mode. A number of oral rinses are usually used which may be titrated by systemic medications. Dexamethasone and budesonide elixirs are two types of corticosteroid rinses able to be used for alleviation of oral ulcers symptoms, lichenoid/ hyperkeratotic reactions, and soft tissue sensitivity.

Topical therapy of the oral cavity by corticosteroid may result in thinning of the oral mucosal and increasing oral sensitivity over the time. Moreover, topical corticosteroid therapy in short-term may result in accumulation of oral yeast species. ${ }^{33}$ Generally, it is suggested that patients to be prophylactically treated by an antifungal troche or rinse, in addition to any systemic antifungal treatment, during treatment of patients with oral topical steroid. Steroid drugs are lipophilic, with the ability to transverse the oral mucosa. In cases of severe oral cGVHD, the mucosal barrier integrity is also a failure. Monitoring of patients for cushingoid features and increased adrenal suppression needs to be performed, and in the case of occurring such symptoms, topical treatments should be modified as accordingly ${ }^{45}$ There are oral rinse formulations designed for directed topical therapies that can be used as systemic immunosuppressive medications, most of which were initially designed for oral lichen planus, which have many similar clinical features with oral cGVHD. ${ }^{46}$

Ointments are another mechanism of topical delivery which are extremely efficient for patients with isolated symptoms of oral cGVHD. In these cases, ointments can be applied

\begin{tabular}{|c|c|c|c|c|c|c|}
\hline Agent & & & & & & \\
\hline Oral rinse & Corticosteroid & $\begin{array}{l}\text { Oral } \\
\text { Ulcers }\end{array}$ & $\begin{array}{l}\text { Oral Ulcers } \\
\text { Soft Tissue } \\
\text { Sensitivity }\end{array}$ & Caries & Hyperkeratosis/Lichenoid & Candidiasis \\
\hline Budesoinde & Yes & Yes & Yes & & Yes & \\
\hline Chlorhexidine & & & & Yes & & \\
\hline Clobetasol & Yes & Yes & Yes & & Yes & \\
\hline Cyclosporine & & Yes & Yes & & Yes & \\
\hline Dexamethasone & Yes & Yes & Yes & & Yes & \\
\hline Dyclonine & & Yes & Yes & & Yes & \\
\hline $\begin{array}{l}\text { Lidobenalox (magic } \\
\text { mouth wash) only } \\
\text { when formulated with } \\
\text { dexamethasone }\end{array}$ & & Yes & Yes & & Yes & \\
\hline Nystatin & & & & & & Yes \\
\hline $\begin{array}{c}\text { Sodium Fluoride } \\
\text { rinse }\end{array}$ & & & & Yes & & \\
\hline Tacrolimus & & Yes & Yes & & Yes & \\
\hline \multicolumn{7}{|l|}{ Other Topicals } \\
\hline Azathioprine Ointment & & Yes & & & & \\
\hline Clobetasol Ointment & & Yes & & & Yes & \\
\hline Clotrimazole Troches & & & & & & Yes \\
\hline $\begin{array}{l}\text { Cyclosporine } \\
\text { Ointment }\end{array}$ & & Yes & & & & \\
\hline Fluoride Gel & & & & Yes & & \\
\hline Thalidomide Ointment & & Yes & & & Yes & \\
\hline
\end{tabular}


as "spot treatment." Currently available topical ointments are azathioprine, tacrolimus, thalidomide, and cyclosporine. As an adjunct to oral treatment, local phototherapy has increasingly gained attention, and resulted in positive outcomes in some cases of dermatological cGVHD. For treatment of oral PUVA, an oral tablet of 8-methoxypsoralen is first administered, which sensitizes the oral mucosa of patients against UV exposure. ${ }^{33}$

Chlorhexidine oral rinse has potent bactericidal attributes. Its alcohol-free version is effective in controlling the oral bacterial flora of patients, especially those having difficulty with oral hygiene (e.g., flossing and brushing) or those with xerostomia who are exposed to dental decay. There are several studies supporting the effectiveness of short- and longterm pilocarpine therapy for salivary agitation in patients with cGVHD. However, using pilocarpine had been associated with increased gastric fluid secretions, making it unsuitable to be used in patients with GI tract GVHD. ${ }^{40}$

\section{Conclusion}

Oral cGVHD is one of the common complications of HSCT. The diagnosis of oral cGVHD is mostly done via clinical findings, but sometimes a biopsy is needed to confirm the condition. Although is typically mild, the manifestations of this disorder are in the forms of hyperkeratotic plaques and confined oral opening secondary to sclerosis. Oral cGVHD is not considered as a determinative factor of patients' survival and its treatment is usually through locally applied corticosteroids. However, the first option to diagnosis of this disorder is conducting clinical trials. New studies on the pathogenesis of cGVHD are underway, and new therapy strategies are under active investigations such as expanding T-regulatory cells, targeting the processes implicated in fibrosis, and targeting at B-cells which are promising for future advances in cGVHD treatment. Establishment of best treatment for cGVHD patients entails well-designed prospective studies.

\section{References}

[01]. Dignan FL, Amrolia P, Clark A, et al. Diagnosis and management of chronic graft-versus-host disease. Br J Haematol. 2012;158:46-61.

[02]. Kuten-Shorrer M, Woo SB, Treister NS. Oral graft-versus-host disease. Dent Clin North Am. 2014;58:351-68.

[03]. Dignan FL, Clark A, Amrolia P, et al. Diagnosis and management of acute graft-versus-host disease. Br J Haematol. 2014;158:30-45.

[03]. Jaglowski SM, Devine SM. Graft-versus-host disease: Why have we not made more progress? Curr Opin Hematol. 2014;21:141-7.

[05]. Paczesny S. Discovery and validation of graft-versus-host disease biomarkers. Blood. 2013;121:585-94.

[06]. Linhares YP, Pavletic S, Gale RP. Chronic GVHD: Where are we? Where do we want to be? Will immunomodulatory drugs help? Bone Marrow Transplant. 2013:48:203-9.

[07]. Travnik R, Beckers M, Wolff D, et al. Graft-versus-Host Disease (GvHD) - an update: Part 1: Pathophysiology, clinical features and classifcation of GVHD. Hautarzt. 2011;62:139-54

[08]. Elad S, Zeevi I, Resnick IB, et al. Valida-tion of the National Institutes of Health (NIH) scale for oral chronic graft-versus-host disease (cGVHD). Biol Blood Marrow Transplant. 2010;16:62-9.

[09]. Michael T. B, Bengt H, Allan J. H, Impact of oral side effects from conditioning therapy before hematopoietic stem cell transplantation: Protocol for a multicenter study. JMIR Res Protoc. 2018;7(4): e103.

[10]. Salmasian H, Rohanizadegan M, Banihosseini S, et al. Corticosteroid regimens for treatment of acute and chronic graft versus host disease (GvHD) after allogenic stem cell transplantation. Cochrane Database Syst Rev. 2010;20:CD005565.
[11]. Arai S, Jagasia M, Storer B, et al. Global and organ-specific chronic graftversus-host disease severity according to the $2005 \mathrm{NIH}$ Consensus Criteria. Blood. 2011;118(15):4242-4249.

[12]. Claudio A, Brent R. L, Stephanie J. L, Peripheral-blood stem cells versus bone marrow from unrelated donors. N Engl J Med. 2013;367(16): 10.1056/ NEJMoa1203517.

[13]. Jacobsohn DA. Optimal management of chronic graft-versus-host disease in children. Br J Haematol. 2010;150(3):278-292.

[14]. Flowers ME, Inamoto Y, Carpenter PA, et al. Comparative analysis of risk factors for acute graft-versus-host disease and for chronic graftversus-host disease according to National Institutes of Health consensus criteria. Blood. 2011;117(11):3214-3219

[15]. Kelli P. A, Geoffrey R. H, Bruce R. B. Chronic graft-versus-host disease: Biological insights from preclinical and clinical studies. Blood. 2017;129:13-21.

[16]. Division of Hematopoietic Stem Cell Transplantation, National Cancer Center Hospital. 2018 update on chronic graft-versus-host disease. Rinsho Ketsueki. 2018;59(10):2300-2306.

[17]. Arora M, Klein JP, Weisdorf DJ, et al. Chronic GVHD risk score: A Center for International Blood and Marrow Transplant Research analysis. Blood. 2011;117:6714-20.

[18]. Ferrara JL, Levine JE, Reddy P, et al. Graft-versus-host disease. Lancet. 2009:373:1550-61.

[19]. Meier JK, Wolff D, Pavletic S, et al. Oral chronic graft-versus-host disease: Report from the International Consensus Conference on clinical practice in cGVHD. Clin Oral Investig. 2011;15:127-39.

[20]. Mays JW, Fassil H, Edwards DA, et al. Oral chronic graft-versus-host disease: Current pathogenesis, therapy, and research. Oral Dis.2013;19:327-46.

[21]. Maria M, José V. B, Yolanda J, et al. Graft-versus-host disease affecting oral cavity. A review. J Clin Exp Dent. 2015;7(1): e138-45.

[22]. Mahesh K, Sujay K. Acute graft versus host disease. Indian journal of dermatology, venereology and leprology. 2011;77(2):217-9.

[23]. Blazar BR, Murphy WJ, Abedi M. Advances in graft-versus-host disease biology and therapy. Nat Rev Immunol. 2012;12:443-58.

[24]. Robert Z, Bruce R. B. Preclinical models of acute and chronic graft-versushost disease: how predictive are they for a successful clinical translation? Blood 2016;127:3117-3126

[25]. Schroeder MA, DiPersio JF. Mouse models of graft-versus-host disease: advances and limitations. Dis Model Mech. 2011:4:318-33.

[26]. Piccin A, Tagnin M, Vecchiato C, et al. Graft-versus-host disease (GvHD) of the tongue and of the oral cavity: a large retrospective study. Int J Hematol. 2018;108(6):615-621.

[27]. Stefanie S, Adela RC, Keith MS. How I treat refractory chronic graft-versushost disease. Blood. 2019;133(11):1191-1200

[28]. JW Mays, H Fassil, DA Edwards, et al. Oral chronic graft-versus-host disease: Current pathogenesis, therapy, and research. Oral Dis. 2013;19(4): 327-346.

[29]. Imanguli MM, Atkinson JC, Mitchell SA, et al. Salivary gland involvement in chronic graft-versus-host disease: prevalence, clinical significance, and recommendations for evaluation. Biol Blood Marrow Transplant. 2010;16:1362-9.

[30]. Julia S, Rosa-María L. P, José G. S, Oral lesions in Sjögren's syndrome: A systematic review. Med Oral Patol Oral Cir Bucal. 2018 Jul 1;23 (4): e391-400.

[31]. Carpenter P. A, Kitko C. L, Elad S, et al. National Institutes of Health Consensus Development Project on Criteria for Clinical Trials in Chronic Graft-versusHost Disease: V. The 2014 Ancillary Therapy and Supportive Care Working Group Report. Biol Blood Marrow Transplant. 2015;21(7):1167-87.

[32]. Diana MC, Claire JD, Michael JS, et al. Use of the National Institutes of Health Consensus Guidelines improves the diagnostic sensitivity of gastrointestinal graft-versus-host disease. Arch Pathol Lab Med. 2017;142:1098-1105.

[33]. Nathaniel T, C Duncan, C Cutler, et al. How we treat oral chronic graftversus-host disease. Blood. 2012;120(17).

[34]. Hull KM, Kerridge I, Schifter M. Long-term oral complications of allogeneic haematopoietic SCT. Bone Marrow Transplant. 2012;47(2):265-70.

[35]. Garming-Legert K, Remberger M, Ringden O, Hassan M, Dahllof G. Longterm salivary function after conditioning with busulfan, fractionated or single-dose TBI. Oral Dis. 2011;17:670-6.

[36]. Fassil H, Bassim CW, Mays J, et al. Oral chronic graft-vs.-host disease characterization using the NIH scale. J Dental Res. 2012;91:S45-S51.

[37]. Laura GC, Renata LF, Carmem B, et al. Oral manifestations compatible with chronic graft-versus-host disease in patients with fanconi anemia. 2015;21(2):275-280

[38]. Hani M, Shahrukh KH, Sharon E, et al. Chronic graft-versus-host disease: Current management paradigm and future perspectives. 2018;25(4):931-948.

[39]. Daniel W, Armin G, Francis A, et al. Consensus Conference on clinical practice in chronic graft-versus-host disease (GVHD): First-line and 
topical treatment of chronic GVHD. Biol Blood Marrow Transplant. 2010;16(12):1611-1628.

[40]. Castellarin P, Stevenson K, Biasotto M, et al. Extensive dental caries in patients with oral chronic graft-versus-host disease. Biol Blood Marrow Transplant. Extensive dental caries in patients with oral chronic graft-versushost disease Biol Blood Marrow Transplant. 2012 Oct;18(10):1573-9 . doi: 10.1016/j.bbmt.2012.04.009 2012

[41]. Hamid R. M, Masoud S, Ladan J, et al. Oral manifestation and dental management in a patient with chronic graft versus host disease with around a 10-year follow-up Biomedical Research and Therapy. 2018;5(6):2370-2377.

[42]. Bollero P, Passarelli PC, D’Addona A, et al. Oral management of adult patients undergoing hematopoietic stem cell transplantation. Eur Rev Med Pharmacol Sci. 2018;22(4):876-887.
[43]. Valéria CC. Cochrane fluoride reviews: an overview of the evidence on caries prevention with fluoride treatments. 2014:5(2):78-83.

[44]. Cochrane NJ, Cai F, Huq NL, et al. New approaches to enhanced remineralization of tooth enamel. J Dent Res. 2010;89(11):1187-1197.

[44]. Wolff D, Gerbitz A, Ayuk F, et al. Consensus conference on clinical practice in chronic graftversus-host disease (GVHD): first-line and topical treatment of chronic GVHD. Biol Blood Marrow Transplant. 2010;16:1611-28.

[45]. Joseph P. Graft-vs-host disease following allogeneic hematopoietic cell transplantation. Blood and Marrow Transplant Program, 2011;18(4):268-276.

[46]. Elad S, Zeevi I, Finke J, et al. Improvement in oral chronic graft-versushost disease with the administration of effervescent tablets of topical budesonide-an open, randomized, multicenter study. Biol Blood Marrow Transplant. 2012;18:134-40. 